\title{
Assessing the digital divide in a Jordanian academic library
}

\author{
Othman Obeidat \\ Al-Balqa' Applied University \\ Faculty of Planning and Administration \\ obeidaothman@yahoo.com.au \\ Paul Genoni \\ Curtin University of Technology \\ School of Media, Culture and Creative Arts \\ p.genoni@curtin.edu.au
}




\title{
Assessing the digital divide in a Jordanian academic library
}

\begin{abstract}
Purpose The research reported attempts to assess the extent and nature of the digital divide as it applies in a developing Arab country.

Design/ methodology /approach The method used is an innovative form of document availability test developed to measure the extent of the digital divide between a service offered by a university library in a developed (western) tertiary education system (Curtin University of Technology, Western Australia), and one offered by a university library in a developing Arab country (Yarmouk University, Jordan). The method tests differences in capacity to deliver content according to format (digital or print), and tests for differences in digital access to both 'international' and 'local' content experienced by users of the two libraries.

Findings The findings indicate the existence of a digital divide, but also suggest that the availability of digital content has helped overcome the substantial scholarly information divide.

Research limitations/ implications The research has implications for academic libraries in developing Arab countries as they attempt to redress the effects of the digital divide.

Originality/value The research uses an innovative methodology for measuring the digital divide, and represents the first attempt to quantify the effects of the digital divide as it impacts upon the users of an academic library in a developing Arab country.

Keywords Digital libraries, document availability test, academic libraries, digital divide, Jordan Paper type Research paper
\end{abstract}

\section{Introduction}

Developing countries are often said to suffer from the disadvantage of a 'digital divide'-the gap between the digitally advantaged (developed) countries and the digitally disadvantaged (developing) countries. In broad terms this digital divide mirrors the technology gap that separates the developed countries from the developing (National Training Information Association 2000; Norris 2001; Warschauer 2001; Hall 2002; Hargittai 2003; Salinas 2003; Munster 2005).

Much of the attention given to the digital divide to date has focused on the most severely disadvantaged countries, particularly those in Africa. The research reported in this paper, however, forms part of a study examining the digital divide in the context of developing Arab countries, with a focus on Jordan. The Arab countries of the Middle East provide an interesting case with regard to digital divide issues as they have an ambivalent status in terms of their 'development'. For whereas they have comparatively productive and wealthy economies by the standards usually applied to developing countries, they are also in a transitional stage of development in terms of providing technology-enhanced human services, including education and communication. A number of governments in the region, including the Jordanian Government, have seized upon the implementation of information and communication technology (ICT) as an essential instrument of development, and many countries of the Arab Middle East are making rapid improvements in their development status. 
One sector in which the impact of ICT implementation is being keenly felt is higher education. The universities of Jordan and other countries of the Arab Middle East are increasingly recognised as hubs of advanced learning and research, both of which are prized by regional governments as being integral to improving economic and social conditions.

At the heart of any university's development and implementation of digital information services is the library. This is true of both developed and developing countries, but to this point the university libraries in developed countries have been more successful in establishing their role in the effective delivery and use of digital information. University-based libraries in developing countries have recently begun to play a similar role in delivering digital content. They can do this both by facilitating access to internationally-sourced digital content, and/or by creating digital repositories and databases of locally-sourced information. As a result, academic libraries in developing countries are increasingly being seen as key 'players' in attempts to bridge the digital divide (Omekwu, 2006; Aqili and Moghaddam 2008).

What has been unclear, however, is the exact extent and nature of the digital divide as it impacts upon developing Arab countries. The research reported in this paper is therefore an attempt to 'measure' the digital divide as it is experienced in a representative Arab country. It approaches this task by assessing the availability of scholarly content provided by Yarmouk University Library in Jordan, and comparing these results with those of a similar study conducted at Curtin University of Technology Library in Perth, Western Australia. The goal of this research is to assess the role that digital libraries serving Jordanian universities can play in reducing the digital divide and thereby assisting the country's universities to optimise their effectiveness with regard to both learning and research.

It should be noted, however, that it is increasingly being acknowledged that the digital divide is about more than just access to ICT. Other important issues that have been suggested include language barriers, literacy barriers, lack of 'local' information in digital content, and lack of culturally appropriate material (Ishaq, 2001; Hargittai, 2003; Salinas 2003; Warschauer 2001; 2003; Munster 2005). In particular, several studies have argued that cultural and social norms in Arab countries can significantly affect the transference of ICTs (Hill et al, 1998; Straub, Loch and Hill, 2001). While these issues form part of the broader study of which the research reported here forms a part, they are not considered in the context of this paper.

\section{Methodology}


It was necessary to devise a method of addressing the objective of this research-that is, to measure the extent of the digital divide as it experienced by users of Yarmouk University Library. On the basis of an extensive literature review it was hypothesised that a measurable effect of the digital divide would be found if the availability of scholarly content at Yarmouk University was compared to the availability of similar content at a university in a developed country. The need for a control study arises because any discussion of the 'digital divide' implies a comparison between the advantaged and disadvantaged. Curtin University of Technology was considered suitable as a representative mid-ranking university in a developed country, offering a modern and integrated digital library service to a student population of a size similar to that of Yarmouk University.

The method used to test for the existence of a digital divide between Curtin University Library and Yarmouk University Library was a document availability test (DAT). The instrument used was a modified version of the DAT as developed by Lancaster (1993), which was in turn based on previous studies by Gaskill, Dunbar and Brown (1934), and Orr and Schless (1972). More recent DAT based research includes Hawkins (2001) and Chiweza (2005).

Some innovation to the DAT method was necessary in order to make it a suitable test for the existence of a digital divide between a developed and developing country. In order to understand the extent and nature of the digital divide necessitated the use of two samples - one to test for differences in the capacity to supply international scholarly content; and another to test for differences in the availability of 'local' content. The former was undertaken in order to measure the difference in availability of the same content from international sources; while the latter allows a measurement and comparison of the extent to which local content has been digitised and is accessible.

Amendments to standard DAT procedure were also required for the current study due to the different technological environments in which libraries now operate when compared to preInternet DATs. Many previous studies were undertaken before the advent of digital content, when the presence of an item within a library's ‘collection’ could be easily deduced. However the prevalence of leased and freely accessible digital content in the libraries included in this study necessitated a revised definition of a 'library collection'. For the purpose of this study an item was deemed to be in the collection of the library if it was listed in the catalogue and with access provided to a physical or digital copy, or if it could be freely accessed from an Internet website from the library or the immediate vicinity. Items that could be provided by the library but at 
additional cost associated with acquisition and delivery (i.e. inter-library loan or commercial document delivery) were deemed not to be in the collection of the library.

The Google and Yahoo search engines were used to test the availability of items on the Internet. As different search engines have differing capabilities to retrieve items from the Internet, a bias could have been introduced had different search engines been used to test sample items in each library. The use of the two most widely used search engines was considered sufficient to replicate the likely Internet search habits of the users of the two libraries and thereby provide an adequate test of their capacity to retrieve sample items.

The criterion used in this study for determining availability on the Internet is retrieval of the full text of items, without cost. For this purpose 'full text' could refer to a complete version of an article in any widely available format, such as Word or PDF.

It is relevant to note that at the time the DAT was conducted between October 2006 and February 2007 the Yarmouk Library collection consisted of approximately 350,000 book titles (many in Arabic); 25,000 non-Arabic journal subscriptions (all as e-journals received by subscription to two major databases); and 600 Arabic journals. Curtin University Library at the same time had a collection of approximately 500,000 books (including 10,500 e-books), and 55,000 journal subscriptions, with most subscriptions available as e-journals from a number of databases. Nearly all of the Curtin Library collection is in English.

\section{Sampling method}

The DAT analysed the availability of three samples of randomly selected citations drawn from academic journals.

Group 1: 500 citations drawn from 'international' journals, to be checked for availability at Curtin University of Technology Library, Yarmouk University Library and on the Internet.

Group 2: 250 citations drawn from Arabic language journals published in Jordan to be checked for availability in the collection of Yarmouk University Library (in either print or electronic format) and on the Internet.

Group 3: 250 citations drawn from Australian journals to be checked for availability in the collection of Curtin University Library (in either print or electronic format) and on the Internet. 
Group 1 items were used to directly compare the availability of the same 'international' items at the two universities. Groups 2 and 3 were used to indirectly compare the capacity of the two libraries to provide researchers with access to items of national or regional interest.

For the purpose of a DAT, a sample population of 750 items (for each library tested, and 1000 items in total) is more than sufficient to assess the capacity of a library to provide access to selected documents. Previous samples used for document availability testing have included 300 citations (Orr and Schless 1972); 296 citations (Penner 1972); and 307 citations (Steynberg 1995). A population of 750 sample items for each library is therefore considered adequate to test the comparative availability of documents in a developed and a developing country, and to allow an objective assessment of the state of the digital divide as it applies to Yarmouk University.

It should be noted that:

- Journals used for citation selection are leading journals in their field. For Group 1 (international journals) these were chosen with the assistance of Thomson's Journal Citation Reports. All journals selected as the source of citations in group 1 were available in both libraries.

- For Australian and Jordanian journals-which are poorly represented in the Journal Citation Reports - other evidence (frequency of citation; perceived reputation) was used to identify appropriate journals.

- In order to ensure a discipline spread, the journals used for harvesting the Group 1 (international) citations were drawn from five disciplines; economics, humanities, education, engineering, and information technology. These disciplines are taught at both Yarmouk University and Curtin University of Technology, thereby ensuring that they will be represented in each library's collection. The citations narrowed to the more humanities and social science focused of these disciplines in Groups 2 and 3 in order to reflect the reliance of these disciplines on more localised content and publishing. 
Table 1: Selected journals, international sample (Group 1)

\begin{tabular}{|l|}
\hline \multicolumn{1}{|c|}{ Title of Journals } \\
\hline Academy of Management Perspectives \\
American Journal of Speech-Language Pathology \\
British Educational Research Journal \\
Canadian Journal of Civil Engineering \\
International Journal of Computer Vision \\
International Journal of Electronics \\
International Journal of Human Resource \\
Journal of Evolutionary Economics \\
Scandinavian Journal of Statistics \\
Trimester Economico \\
\hline
\end{tabular}

Table 2: Selected journals, Jordanian Sample (Group 2)

\begin{tabular}{|l|}
\hline \multicolumn{1}{|c|}{ Title of Journals } \\
\hline Abhath Al-Yarmouk \\
Almanarah-Al-Albayt University \\
Derasat- University of Jordan \\
Journal of Irbid University \\
Muta'ah for Research and Studies \\
\hline
\end{tabular}

Table 3: Selected journals, Australian Sample (Group 3)

\begin{tabular}{|l|}
\hline \multicolumn{1}{|c|}{ Title of Journals } \\
\hline Australian Journal of Education \\
Australian Journal of Language and Literacy \\
Australian Literary Studies \\
Journal of Australian Studies \\
Labour History \\
\hline
\end{tabular}

\section{Sampling of citations}

The study employed systematic sampling in order to determine the sample citations. The first step in the systematic sampling of citations was to establish which articles within the selected journals would be selected as the source of citations. Beginning from the first article in the most recent issue of the chosen journal title, every fifth article was selected, counting from the first article in the most recent issue available at that time.

The second step was to establish which citations from the list of references (bibliography) for each selected article would be sampled. Since (for the national journals) 250 citations were required, it meant that 50 citations would be selected from each of the five journals. Using the formula $(k=N / n)$ for each subject area, 250 citations (the $N$ total per subject) were divided by 50 citations (the $n$ population per chosen journal title) and $k$ was found to be equal to 5 . Therefore, every fifth citation was selected, beginning with the first citation in the first article of the most recent issue. If, by using this method, the first five sampled articles did not produce the required 
50 citations, this method of selection was continued to include additional articles. Using this method, 500 items were selected from the international journals to be checked at both universities; 250 citations were sampled from the Jordanian journals to be checked for availability at Yarmouk University, and 250 citations were sampled from the Australian journals to be checked for availability at the Curtin University of Technology Library. The sample items in all three groups were also searched for their availability from free Internet resources

\section{Results}

\section{Document availability test (International sample - group 1)}

Figure 1 below displays a flowchart showing the search procedures used for the sample items selected from citations in the international journals. It includes a summary of the results obtained from both libraries indicating the number of cases in which the libraries can provide immediate access to an item from their collections in either print or digital form, or provide access from the Internet.

The items in the international sample were comprised of 342 (68.4\%) journal articles; 106 (21.2\%) books or chapters within books; 15 (3\%) web-based documents; 18 (3.6\%) conference papers, and 19 (3.8\%) other (i.e. a thesis, dissertation or government publication). The sample items also consisted of 495 (99\%) in English, and 5 (1\%) in other European languages. 
Figure 1: International sample items (Group 1), $n=500$

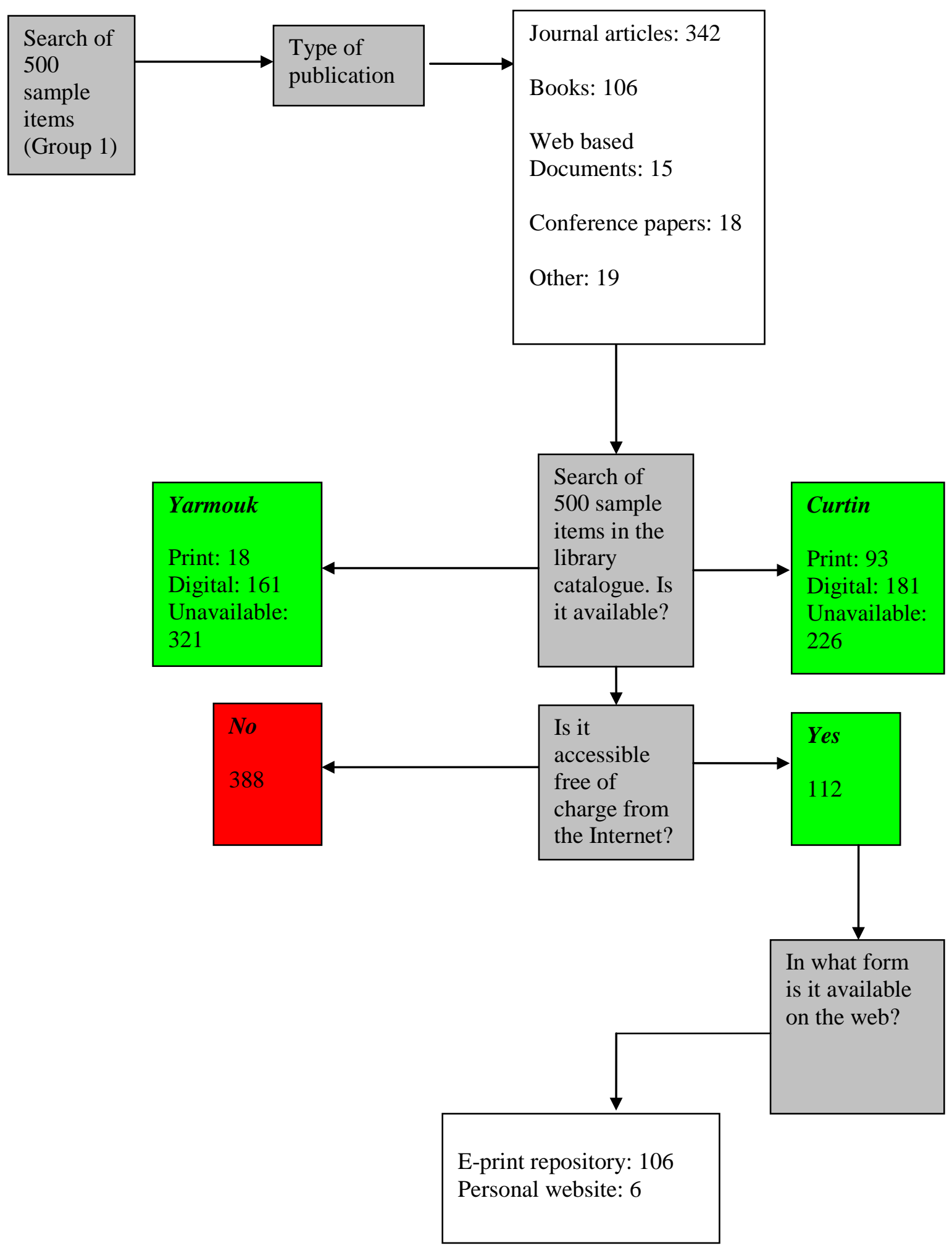

These results for the holdings of the two universities can also be represented and compared by using the Venn diagrams in Figures 2 and 3. 
Figure 2: International Sample (Group 1) availability at Curtin University, n=500

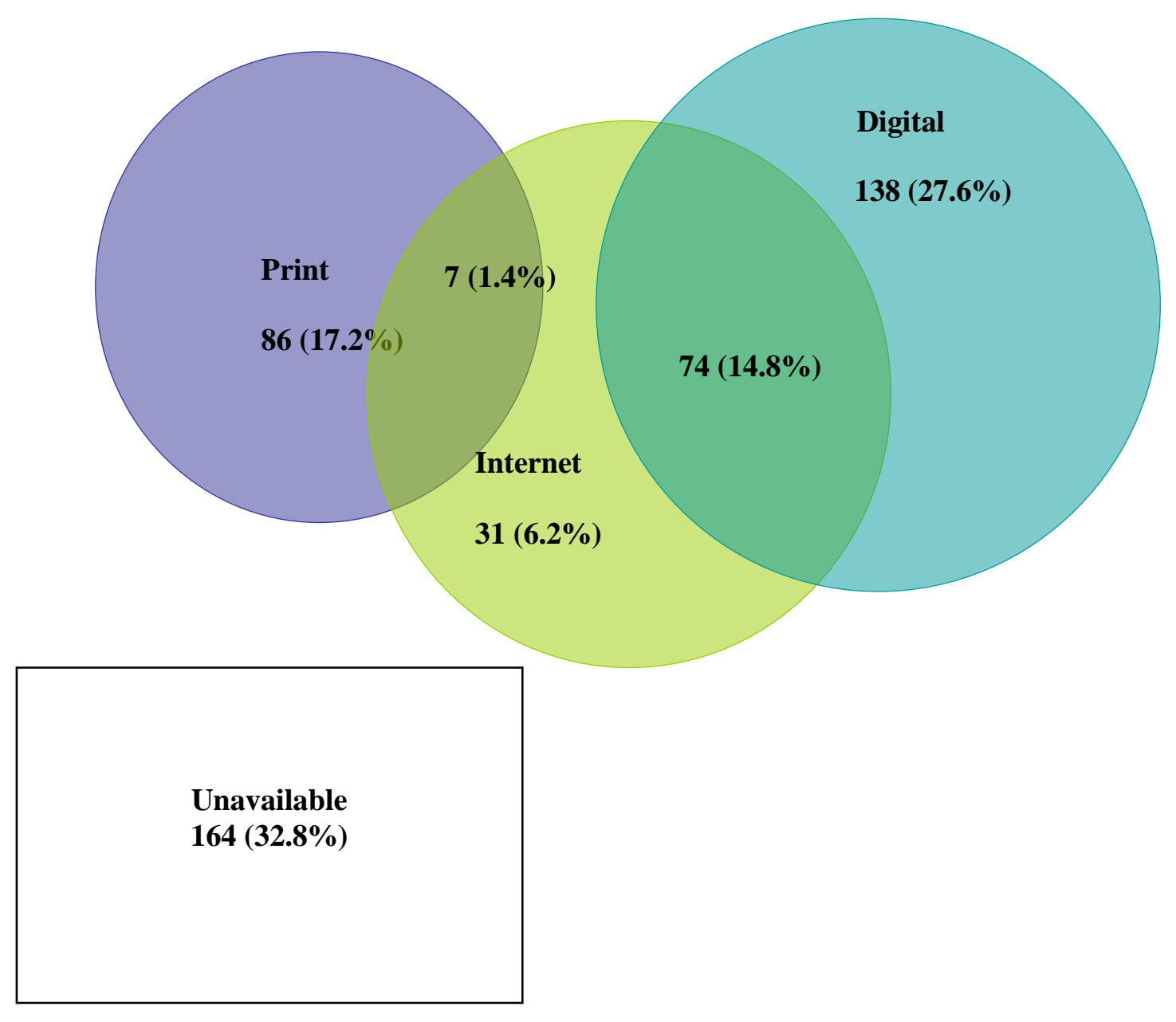




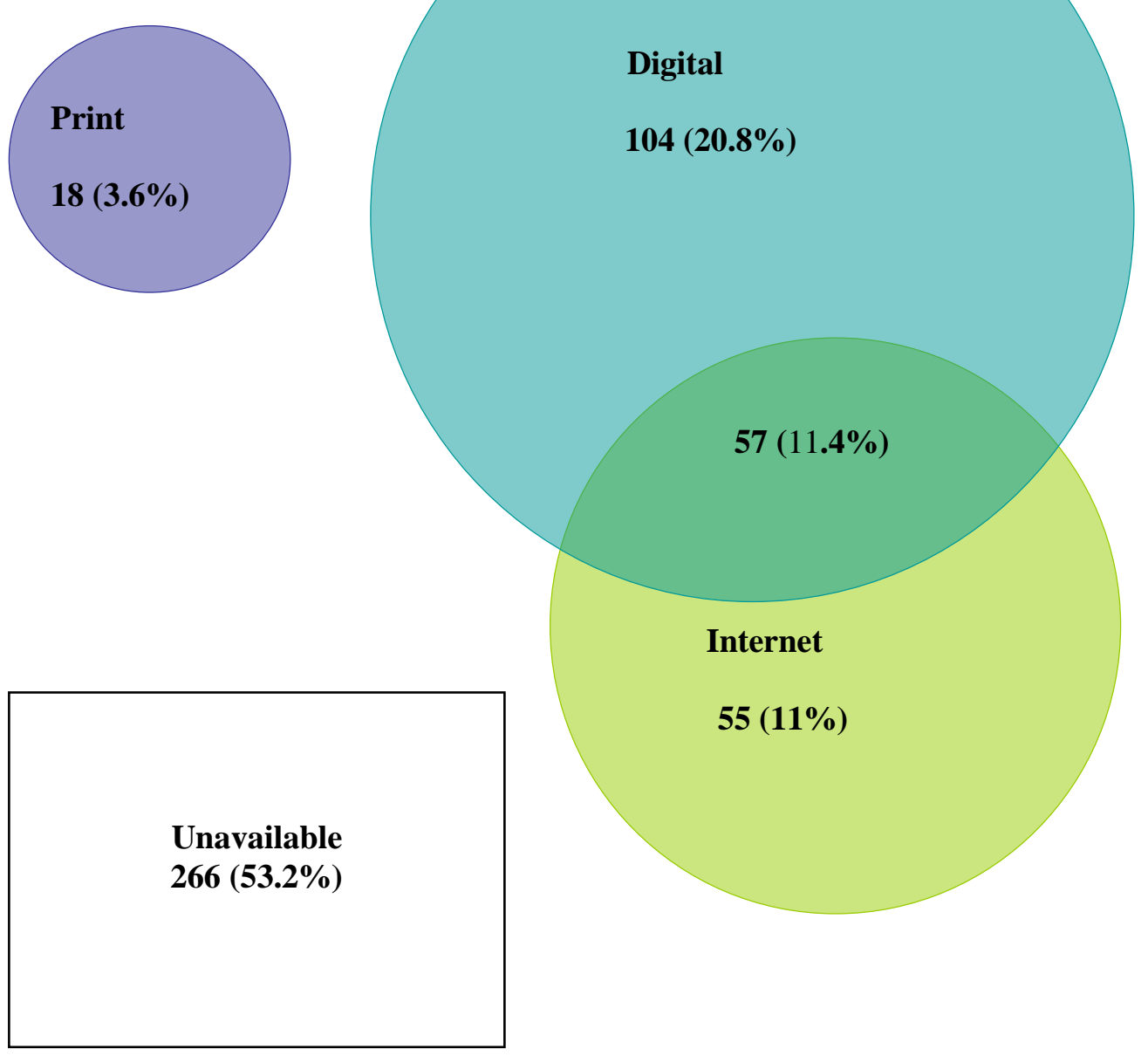

The results indicate that based on a comparison of this sample of 500 international citations, Curtin University Library (61\%) was able to provide users with a greater amount of direct access (i.e. from the library's own collection) to the sample items than was Yarmouk University Library (35.8\%).

While the availability of sample items within a library is relevant in assessing capacity to 'deliver' information, the format in which the items are made available also plays a role in assessing the nature of any information divide that may exist between the two libraries, and in determining the extent to which this divide can be attributed to a technology gap. It was therefore necessary to investigate whether the sample items identified as being in the respective collections were available in print or digital form. The results indicate that Curtin University Library holds a 
much greater number $(18.6 \%$; $n=93)$ of the sample of international items in print form than does Yarmouk University Library (3.6\%; n=18) [1].

Of the 93 sample items held in print form at Curtin University Library, 51 were held as journals (14.9\% of the journal articles included in the sample items), and 42 as books or chapters within books (39.6\% of the books included in the sample items). In contrast, of the 18 sample items that were successfully identified as being available in Yarmouk University Library, only 1 was found in a print journal article (0.03\% of all journals in the sample items), and 17 were printed books or chapters within books (16.0\% of all books in the sample items).

It is apparent from these results for the 500 'international' items available in print that users of the Curtin University Library have a substantial advantage over those of the Yarmouk University Library. This is likely to be the result of:

- Curtin University, having been founded a decade prior to Yarmouk University, has had a longer period in which to establish its library collection.

- Greater expenditure on library content at Curtin University in an attempt to support learning and research at a level that could not be sustained at Yarmouk University.

- A more focused acquisition of the type of items included in the international sample, which is dominated by English language items.

The results of the DAT for the international citations confirms that the print journal collection of Yarmouk University Library is particularly poor, with a negligible collection of backsets of English language journals in print form.

The sample items categorised as available in digital form in the library collection included those located in full text databases and other digital formats which are either owned or subscribed to by the library at the time of the survey. The DAT results indicate that for both Curtin and Yarmouk University Libraries it is more likely that items would be available from their collection in digital form rather than print. Curtin was able to provide $42.4 \%(n=212)$ of all sample items in digital form, as compared to $18.6 \%$ in print. Yarmouk was able to provide $32.2 \%(n=161)$ in digital form, as compared to $3.6 \%$ in print. For neither library were any of the sample items available in both print and digital forms, although it is apparent that both libraries would have examples of content duplicated in this way.

It is apparent from these figures that Curtin University Library users can access a greater amount of the international sample items in digital form. What is also the case, however, is that the 
Yarmouk users receive a bigger comparative advantage than Curtin users when the digital items are summed with the print content. This is demonstrated in Figure 4.

Figure 4: Items in International sample (Group 1) available in print or digital form

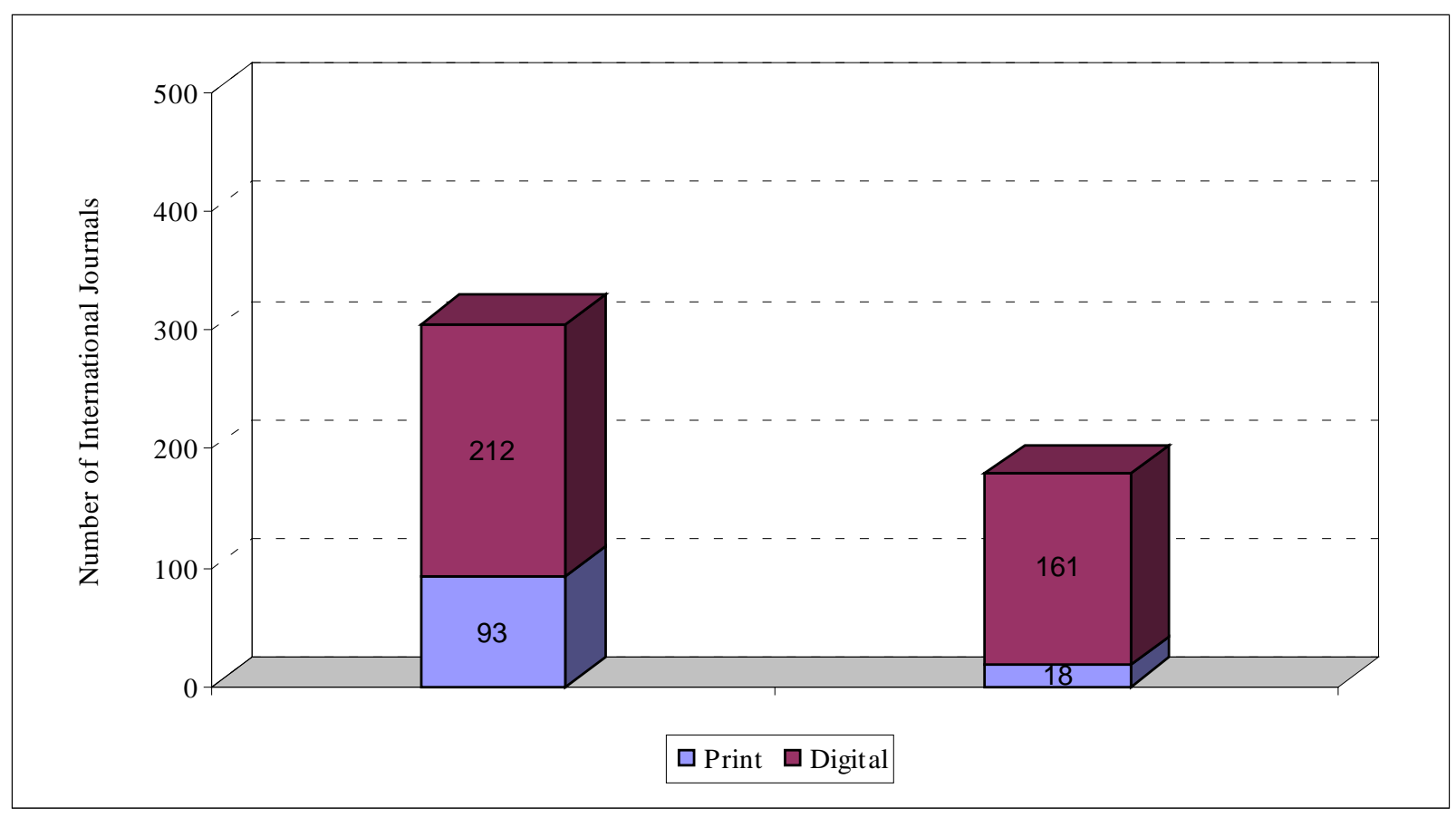

Of the items available from the Curtin Library collection, $69.5 \%$ are digital; while of those available from the Yarmouk Library collection, 89.9\% are digital. This comparison of the percentage of content supplied in digital format works in Yarmouk's favour due to their paucity of 'international' journals in the collection prior to the advent of large databases of full text periodicals. By acquiring just two such databases (at the time the study was conducted) Yarmouk University Library has been able to rapidly compile a representative collection of current international journals, including in many cases substantial backsets. While their capacity to deliver items in digital format does not equal that of Curtin University Library, they have been able to use the availability of digital databases to begin to close, in comparative terms, the considerable information deficit they had previously experienced with regard to 'international' content.

All 500 sample items in Group 1 (international sample) were also searched on the Internet in order to determine if those items could be accessed in full text from a website free of charge. An item was recorded as available if it could be determined that the item was substantially similar to the published version (i.e. it did not have to be a pdf of the published item). 
The DAT found that exactly the same 112 sample items (22.4\% of all sample items) were freely accessible when using the Internet at both universities. That the result was the same for both universities indicates that for this sample there was no blocking of access by either university that prevented access to the relevant items.

As expected, there is duplication for both libraries between items available on the Internet and those that were available in print or digital form in their collections. The overlap for Curtin Library was 81 of the 112 items (74 print and 7 digital), and for Yarmouk Library was 57 items, all duplicating items in the Library's digital collection. The result of this duplication is that of the 112 items available on Internet, 31 only were additional to the Curtin collection, while 55 were additional to the Yarmouk Collection. The impact of this duplication on the net availability of items at the two libraries is represented in Figure 5.

Figure 5: Sample items in Group 1 (International sample accessed in print, digital, and Internet forms (duplicates removed.)

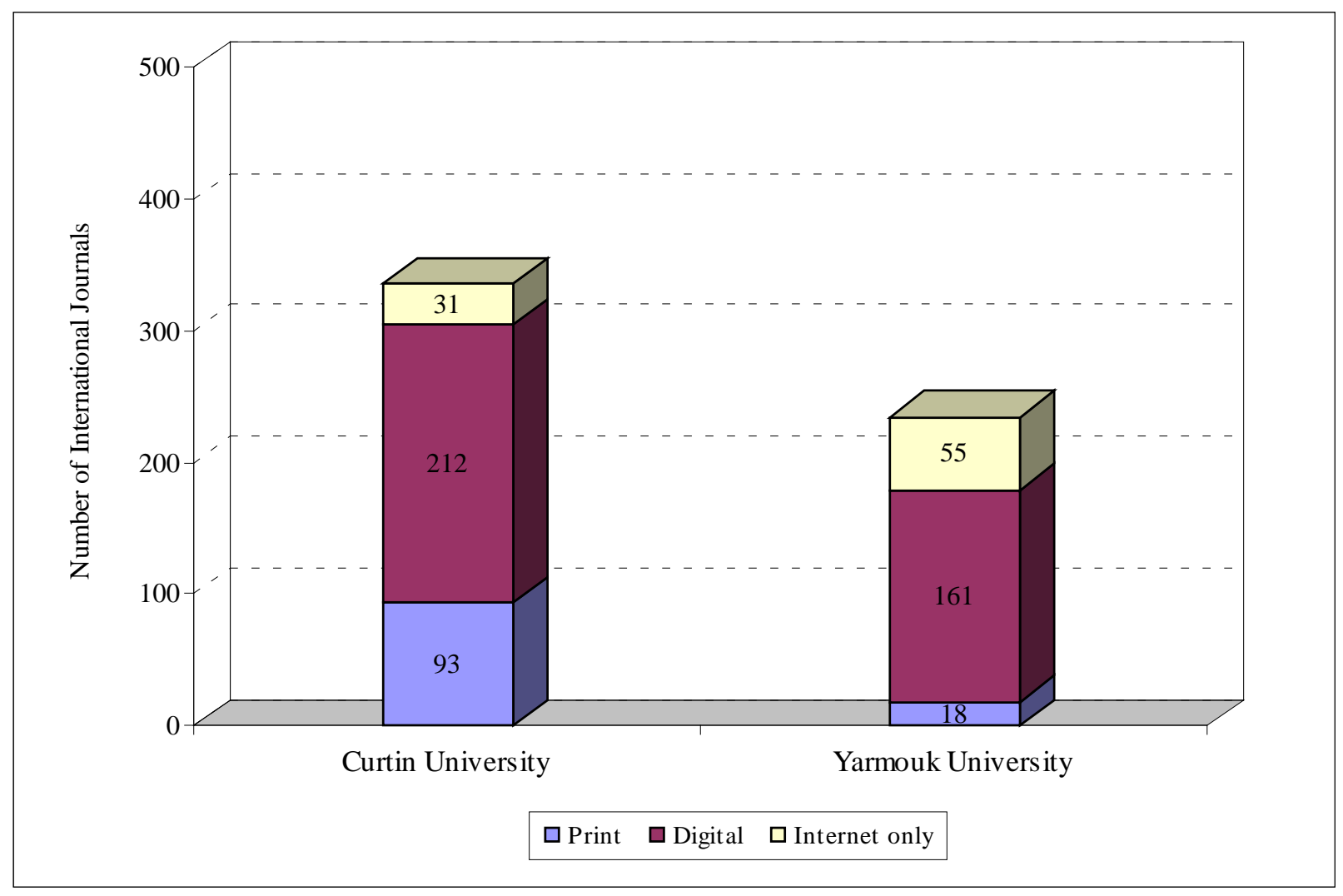

These results of the test for available items from Group 1 suggest that in terms of supplementing access to international scholarly material, that the countries that are likely to receive the greatest advantage from the Internet are those with less developed library collections. This is achieved 
because they have less duplication with existing collections. That the items retrieved from the Internet were mainly journal articles sourced from institutional repositories and personal websites indicates that the open access movement is having a beneficial impact with regard to access to this category of international scholarly material. And while this impact is enjoyed by the users of both libraries, it is of greater comparative benefit to the users of Yarmouk University Library.

The overall results indicate that for all content in digital form (i.e. either part of a library's collection or available from the Internet) Curtin University Library was able to provide access to 243 (48.6\% of all sample items) separate items, and Yarmouk University Library to 216 (43.2\%) separate items. While Curtin users therefore receive the greater beneficiary in absolute terms, it is arguable that in comparative terms Yarmouk users are the major beneficiaries of digital content. Access to digital material has enhanced the availability of material at Curtin Library by 161\%; while at Yarmouk Library the increase is $1100 \%$ [2].

\section{Document availability tests, Jordanian sample (Group 2) and Australian sample (Group 3)}

Figures 6 and 7 illustrate the search procedure for the sample items comprising Group 2 (Jordanian sample) and Group 3 (Australian sample). They also include a summary of the results obtained from the search of the catalogues of the two libraries for the relevant sample items (Group 2 at Yarmouk University Library and Group 3 at Curtin University Library), plus the sample items available free of charge from the Internet at each University. 
Figure 6: Jordanian sample items (Group 2), $n=250$ )

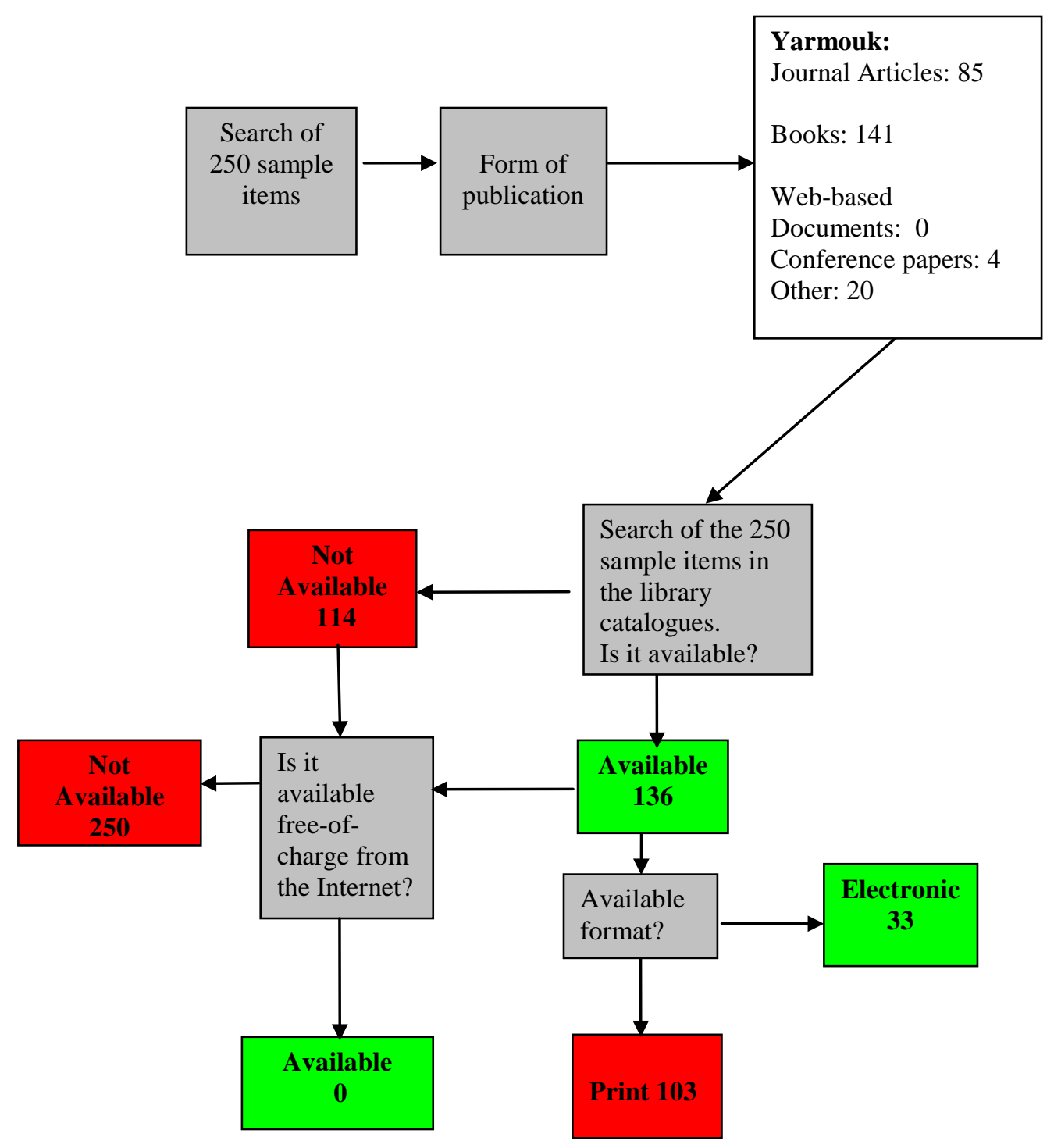


Figure 7: Australian sample items (Group 3), n=250)

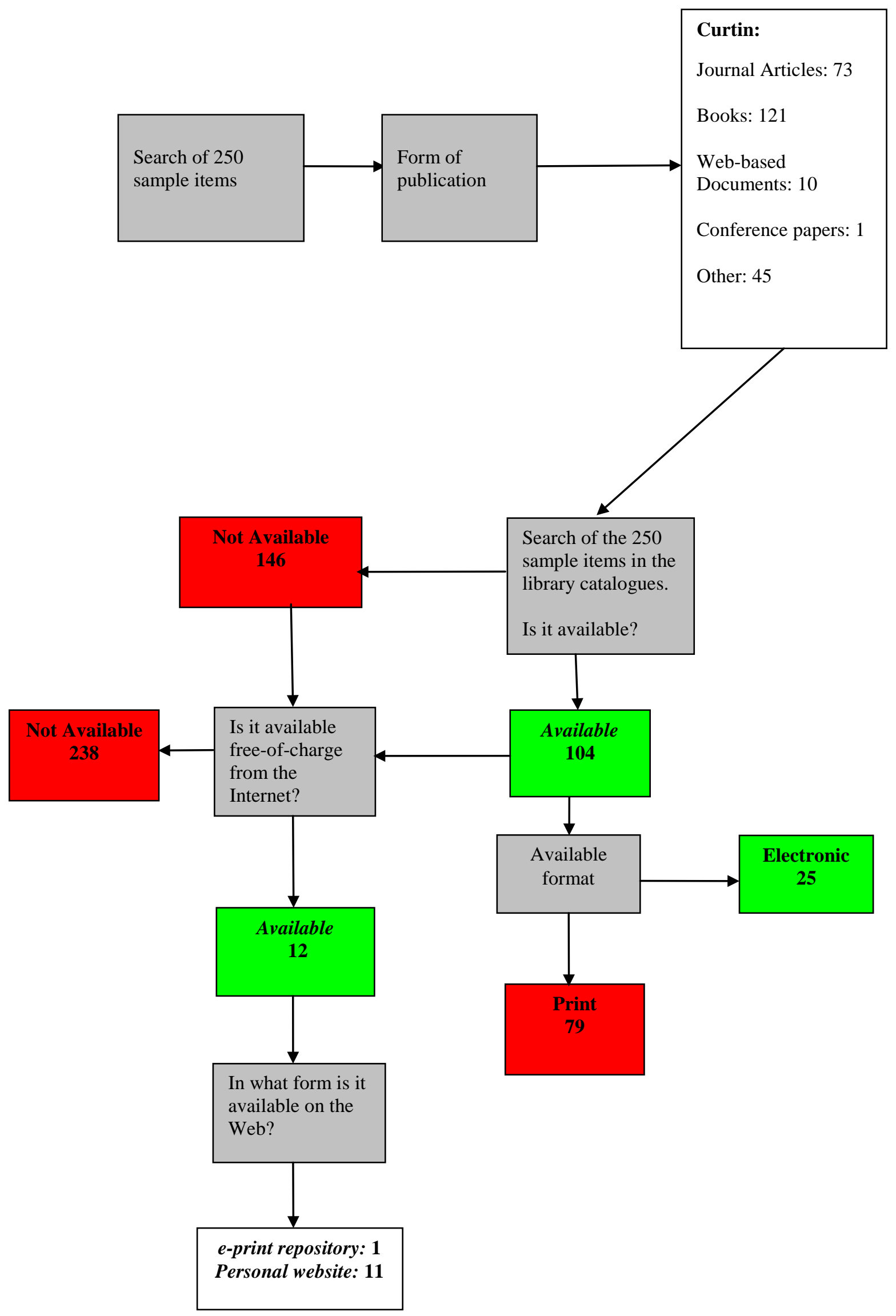


The results for the two samples indicate that Yarmouk University Library was able to provide access to a greater number of items $(n=136,54.4 \%)$ from its collection than was Curtin University Library (n=104, 41.6\%).

\section{Figure 8: Jordanian sample items (Group 2): availability at Yarmouk University} Library

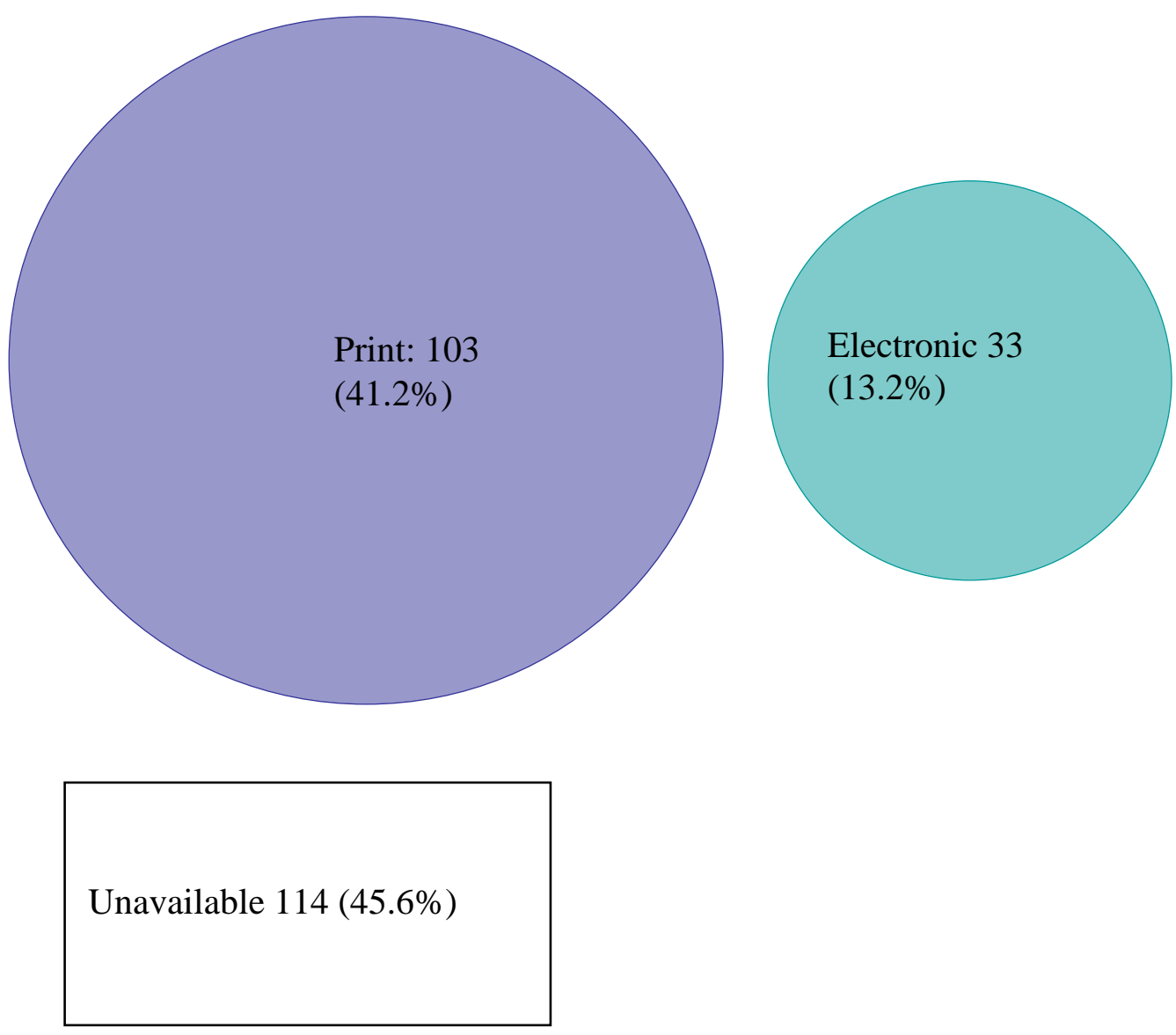

These results indicate that for these 'local' items Yarmouk University Library was more successful in meeting users' needs from their print collection than the electronic collection. The $41.2 \%$ of items retrieved in print form is in sharp contrast to the result for the international sample (Group 1) at Yarmouk University Library, where only 3.6\% of sample items were located. It is apparent that these contrasting results reflect the difference in the nature of the two samples, with the international sample being largely English language 
items, while the local sample consists of Arabic items. It is also the case that Yarmouk University has in recent years become a deposit library for print and digital scholarly journals from Arab countries, a role that has substantially impacted its collecting of local and regional material.

The result of 33 items (13.2\%) being available from library databases also indicates the extent to which the digitisation of Arabic journals, a project led by Yarmouk Library, has progressed. It is the case, however, that no sample items were retrievable free of charge from the Internet. This is a strong indication of the lack of development of open access or institutional repositories for Jordanian and/or Arabic content. Recent studies have pointed to the potential of open access to scholarly content as an important means of addressing the digital divide in developing countries (Arunachalam 2004; Ghosh and Kumar 2007).

An analysis of the 136 Group 2 items identified from the catalogue of Yarmouk University Library as being available indicates $71 \%$ were books or book chapters, and $25 \%$ were journal articles. This contrasts with the Group 1 (international sample) for which $10 \%$ were books or book chapters, and 85\% from journal articles. This difference in source material may reflect a scholarly culture that still relies more on books than journals for communicating scholarly content. 
Figure 9: Australian sample items (Group 3), availability at Curtin University Library

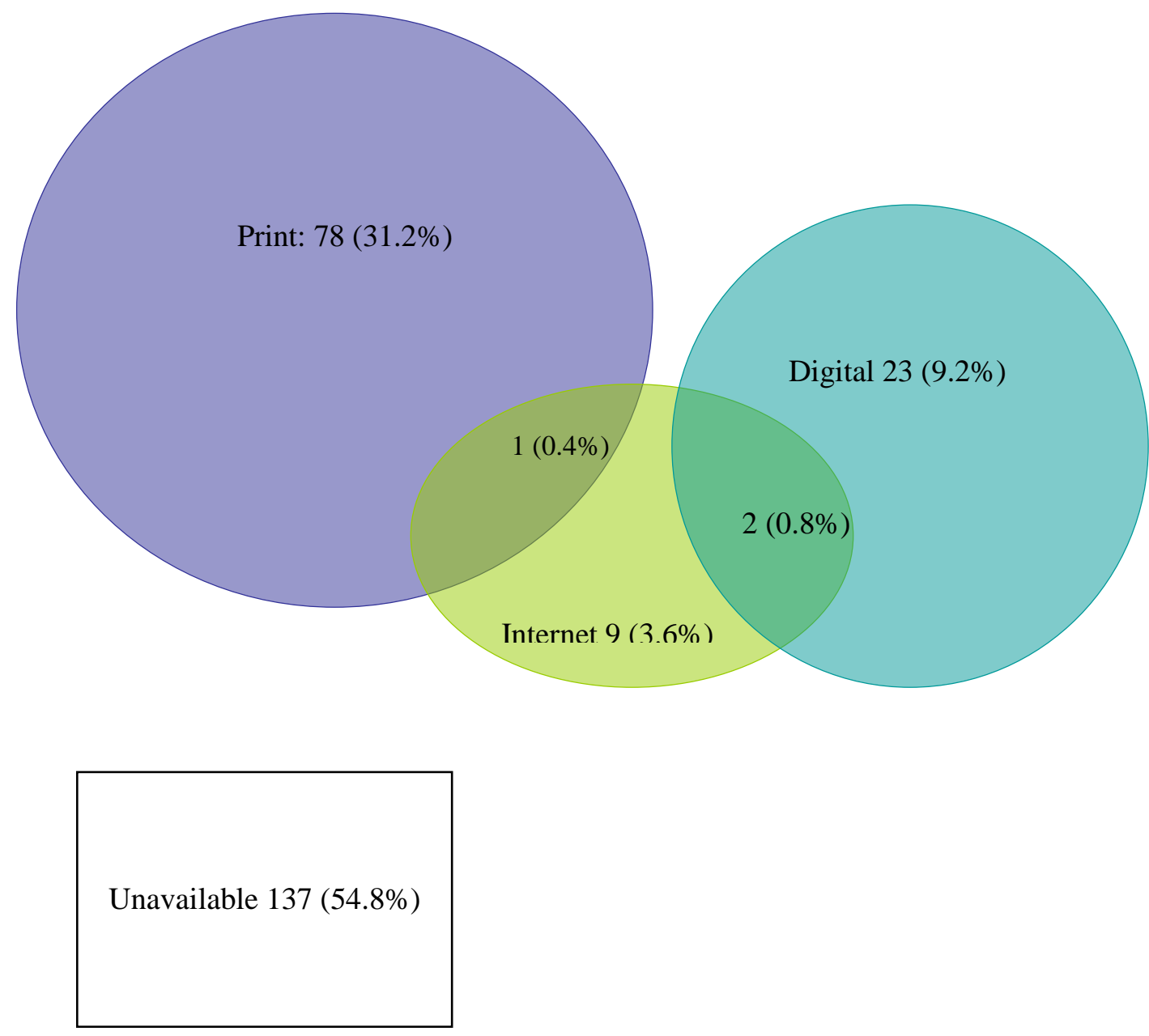

In addition to the items located in the Curtin Library’s collection, 12 (4.8\%) were also able to be located on the Internet, of which 3 duplicated items in the Library's collection. This result contrasts with those obtained for Group 1 (international sample), wherein $22.4 \%$ of sample items were found to be available on the Internet. This difference in rates of open access availability is likely to be found in the disciplinary differences between sample items in Group 1 and Group 3. It is notable that the bulk of the Internet/collection overlap (74 of 81; 91.4\%) in Group 1 sample items was with items available in the Library's digital collection, suggesting that the electronic availability of international items (many from the sciences) is significantly greater than that of Australian social science/humanities items. It 
is therefore likely the figures reflect a difference between disciplinary citation practices rather than the country of origin, with the more recent sample items from Group 1 have a higher probability of being included in free web sites such as institutional repositories or personal webpages.

This disciplinary based difference in the characteristics of the literature included in the sample groups is also evidenced by the type of publication in each group. The international sample includes 342 (68.4\%) journal articles as sample items, whereas the Australian sample includes only 73 (29.2\%) journal articles. It is largely journal articles that have been used to populate open access repositories, and disciplines that depend on non-journal material are therefore less likely to find their content available in this way

\section{Comparison of results at Yarmouk University Library (Group 2) and Curtin University Library (Group 3)}

As discussed, in order to measure the extent of a digital divide, it is necessary to identify items both in terms of their availability and the format in which they are available. A comparison between the two libraries indicates the comparative difference in making 'local' sample items available in various formats. 
Figure 10: Sample items from Group 2 and Group 3, availability at Curtin University Library and Yarmouk University Library

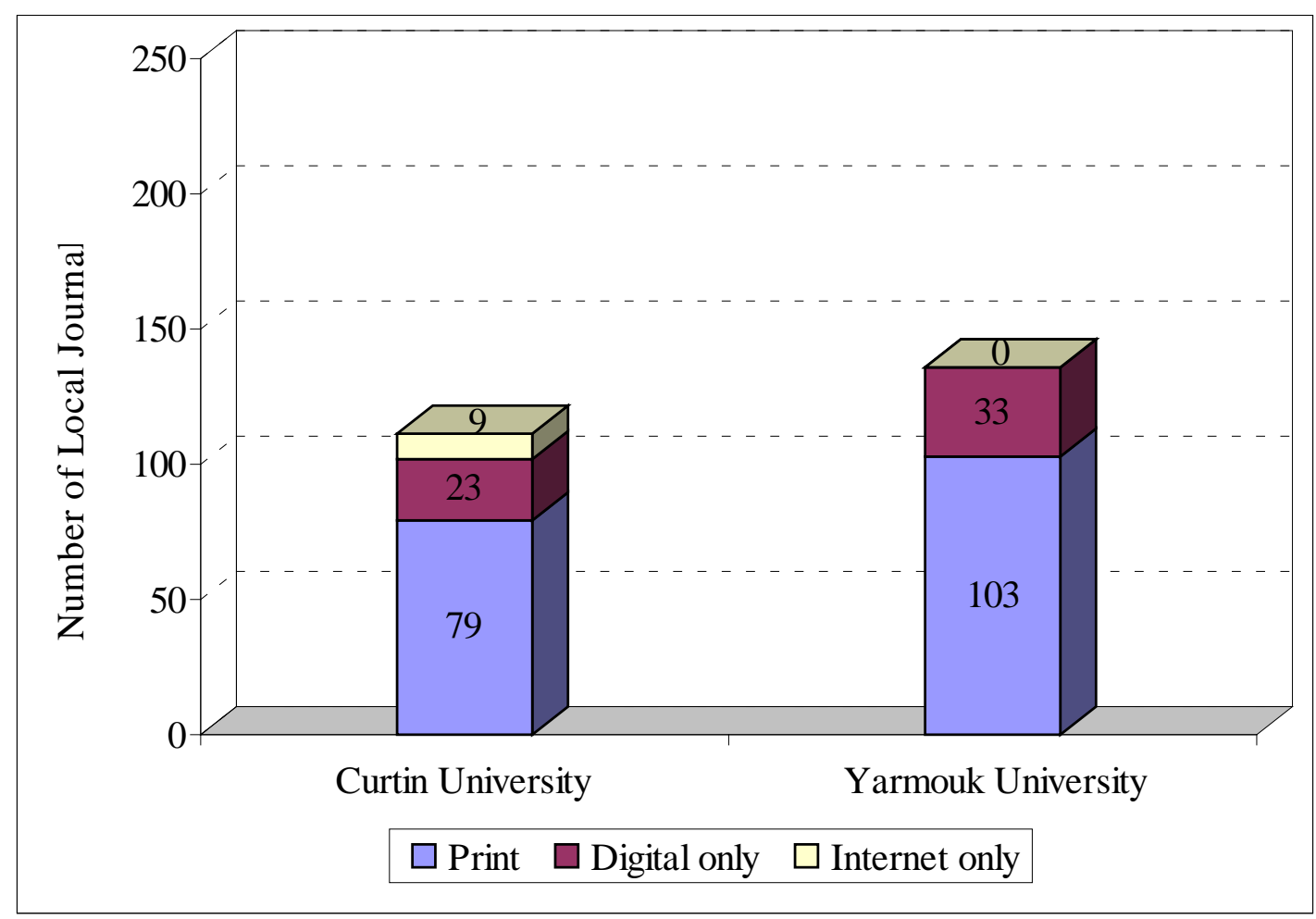

Figure 10 illustrates that for sample items included in Groups 2 and 3, both universities had more available in print rather than electronic form. This is in contrast to the Group 1 results where both libraries were able to provide more items from their collections digitally rather than in print.

The greater success in locating items from the collection at Yarmouk University Library is perhaps unexpected. It is likely to be explained by the different scale of scholarly publishing originating from Australia and Jordan. That is, the greater number of journals and books produced by the Australian scholarly publishing industry means that it is difficult for any but the very largest research libraries to collect this material comprehensively. The Arabic scholarly publishing industry considerably less developed and produces a smaller number of journals and books, and therefore a university library such as that at Yarmouk (boasting a large collection by Arab region standards) can reasonably expect to collect a higher proportion of published material. A related phenomenon is that citation patterns in Arabic are likely to be more repetitive, in that there 
is a narrower range of journals from which citations might be derived. These factors will almost inevitably result in major Arab university libraries holding a greater percentage of cited material in print form.

What also appears to be the case, however, is that the development of open access repositories is proceeding much more slowly for Jordanian content than Australian content. Therefore whereas the free Internet produced a comparatively greater advantage for users of Yarmouk Library than Curtin Library in terms of its capacity to provide 'additional' access to items from Group 1 (international sample), the situation is reversed when it comes to their 'national' collections. Whereas Curtin Library users benefit by having access to nine (3.6\%) additional items, users of Yarmouk Library receive access to no additional items.

\section{Conclusion}

A total of 1000 sample items divided into three groups was searched using the catalogues of Yarmouk University Library and Curtin University Library. In the first instance, the search focused on the availability and access of the selected sample items from each library's print and digital collections. In the second instance, a further search was conducted using popular Internet search engines to ascertain the availability of the sample items as free web-based resources.

In terms of assessing the digital divide analysis of the data indicates the following:

1. Prior to the advent of digital content there was a substantial 'information divide' between the two universities and their libraries, measured by Curtin Library's far greater capacity to provide print based access to international content.

2. Access to international sample items (Group 1) located in the collections of both libraries was greater from digital sources than print sources. For local content (Groups 2 and 3) located in each library, the print collections provided greater access than digital. This is likely to reflect a combination of disciplinary factors and the relatively slower progress that is being made with the digitisation of these 'local' sources compared to those with an international readership. 
3. While the 'free' Internet may be a useful and widely used information source, in terms of providing scholarly content it does not as yet serve to provide substantial access compared to the content collected by libraries. This is particularly the case for Arabic material, with not one of the 250 'local' items checked at Yarmouk University being available on the Internet.

4. Curtin University Library users enjoy the benefit of greater access to international items from their digital collections, but the situation is reversed with regard to 'local' items where the advantage is with Yarmouk University Library users.

The situation with regard to drawing conclusions about the existence and extent of a digital divide is not straightforward. The complicating factors include Yarmouk University Library's role as a deposit centre, and the different scale of scholarly publishing in Australia and Jordan (or indeed, in English and Arabic). A conclusion on the results of the DAT alone, however, suggests that while there is evidence of a digital divide, it appears that the advent of digital content has had the affect of narrowing rather than exacerbating the information divide that previously existed between users of Yarmouk University Library and Curtin University Library. This narrowing of the information divide is particularly pronounced with regard to the international materials, and results from both the very poor previous state of print collections at Yarmouk University Library, and the comparatively greater benefit that users of Yarmouk University Library receive from content made freely available on the Internet. This conclusion is further complicated, however, in that in one critical regard - the development of open access Arabic contentthere has been little development as yet, thereby disadvantaging the users of Yarmouk University Library with an interest in Arabic scholarship. Librarians and scholars in Jordan with an interest in promoting Arabic learning and research should make the development of open access repositories for both old and recent scholarship a priority.

\section{Notes}

1. In reality the difference in the capacity of the two libraries to provide items from their print collections is likely to have been reduced by the advent of digital content. This is because the Curtin Library has discarded print copies of journals that are now acquired electronically, meaning their comparative advantage in this regard is less than it would have been. 
2. Again is should be noted that the net gain in content by Curtin Library is likely to be less than indicated by this result, due to the Library's policy of discarding print copies of journals to which they have acquired electronic subscriptions.

\section{References}

Aqili, S. and Moghaddam, A. (2008), "Bridging the digital divide: the role of librarians and information professionals in the third millennium", The Electronic Library, Vol. 36 No. 2, pp. 226-237.

Arunachalam, S. (2004), “Open access and the developing world”, The National Medical Journal of India, Vol. 17 No. 6, pp. 289-291.

Chiweza, D. S. (2005). The Potential for Virtual Library Services to Promote Teaching and Research and Reduce the Digital Divide: A Case Study of the University of Malawi. Masters thesis, Curtin University of Technology, Perth.

Gaskill, H., Dunbar, R. H. and Brown, C. H. (1934), "An analytical study of the use of a college library”, Library Quarterly, Vol. 34 No. 4, pp. 564-587.

Ghosh D. and Kumar, A. (2007), "Open access and institutional repositories a developing country perspective: a case study of India.”, IFLA Journal, Vol. 33 No 3, pp. 229-250.

Hall, P. (2002), "Bridging the digital divide, the future of localization”, Electronic Journal of Information Systems in Developing Countries, Vol. 8 No. 1, pp. 1-9, available at: http://www.ejisdc.org/ojs2/index.php/ejisdc/article/view/40 (accessed 9 January 2010).

Hargittai, E. (2003), “The digital divide and what to do about it.”, in D.C. Jones (Ed.), The New Economy Handbook. San Diego: Academic Press.

Hawkins, B. (2001), "A view on the ecology of Information", in D. B. Marcum (Ed.), Development of digital libraries: An American perspective. Westport, Connecticut: Greenwood Press, 187-210.

Hill, C., Loch, K., Straub, D. and El-Sheshai, K. (1998), “A qualitative assessment of Arab culture and information technology transfer”, Global Information \& Management, Vol. 6 No. 3, pp. 29-38.

Ishaq, A. (2001), “On the global digital divide”, Finance and Development: A Quarterly Magazine of the IMF, Vol. 38 No. 3, available at:

http://www.imf.org/external/pubs/ft/fandd/2001/09/ishaq.htm (accessed 9 January 2010).

Munster, I. (2005), “The digital divide in Latin America: a case study”, Collection Building, Vol. 24 No. 4, pp. 133-136.

National Training Information Administration (2000), Falling Through the Net: Defining the Digital Divide: Washington, DC: U.S. (Department of Commerce).

Norris, P. (2001), Digital Divide: Civic Engagement, Information Poverty, and the Internet Worldwide. Cambridge: Cambridge University Press.

Omekwu, C. (2006), "Managing information and technology: critical roles for librarians in developing countries”, The Electronic Library, Vol. 24 No. 6, pp. 847-863.

Orr, R. and Schless, A. (1972), "Document delivery capabilities of major biomedical libraries in 1968: results of a national survey employing standardized tests", Bulletin of Medical Library Association, Vol. 60 No. 3, pp. 382-422.

Penner, R. (1972), “Measuring a library's capability”, Journal of Education for Librarianship, Vol. 13 No. 1, pp. 17-30.

Salinas, R. (2003), “Addressing the digital divide through collection development", Collection Building, Vol. 22 No. 3, pp. 131-136. 
Steynberg, S. and Rossouw, S. (1995), “Testing Orr's document delivery test on biomedical journals in South Africa”, Bulletin of Medical Library Association, Vol. 83 No. 1, pp. 78-84.

Straub, D., Loch, K. and Hill, C. (2001), "Transfer of information technology to the Arab World: a test of cultural influence modeling”, Journal of Global Information Management, Vol. 9 No. 4, pp. 6-28.

Warschauer, M. (2001), "Language, identity, and the Internet”, Mots Pluriels, Vol 19, available at : http://motspluriels.arts.uwa.edu.au/MP1901mw.html (accessed 10 January 2010).

Warschauer. M. (2003), "Dissecting the digital divide: a case study in Egypt special issues: remapping the digital divide”, The Information Society, Vol. 19 No 4, pp. 297-293. 